\title{
ADVANCE DIRECTIVES IN MENTAL HEALTH CARE
}

\section{S. Gyawali*, S. Mohan K., R.Ganesh, P.Rajhans, K. S. Deb; All India Institute of Medical Sciences, New Delhi, India}

Introduction:

The ratification of United Nations Convention in Rights of Persons with Disabilities, led India to introduce Mental Healthcare Act, 2017 (MHCA). The fundamental change seen in MHCA is its focus on maintaining patient autonomy through the introduction of Advance Directive (AD). AD is meant to ensure that a person's preferences for treatment are followed in situations where $s /$ he is not competent to do so in future. However, its implementation in resource limited country comes with its own pitfalls.

In this background, it is pertinent to understand the implementation of $\mathrm{AD}$ globally, vis-à-vis the potential problems and uniqueness of Indian AD.

Principles of Advance Directive in Mental Healthcare:

Promotes participation

Promotes non-discrimination

Enhances mutual acceptability of treatment decisions by reducing coercion Increases treatment collaboration, motivation and adherence Helps avoid conflict over treatment and medical issues

Variations in AD:

Nature of $A D$ Instructional: How to/not to treat

Health care proxy: Who will make decision

Hybrid: Instructional + health care proxy

Travelling care plan: Based on past response to treatment

Ulysses contract: Follow instruction, no matter what

Involvement of Yes, content must be verified by a professional for it to be care provider in valid

making $A D$

No, content need not be verified

Need to prove Yes, need to assess competence for a valid AD

competency No, competence need not be assessed

Legal status Can be bound legally or not

Problem Areas in Mental Healthcare AD: Declaration of Competence

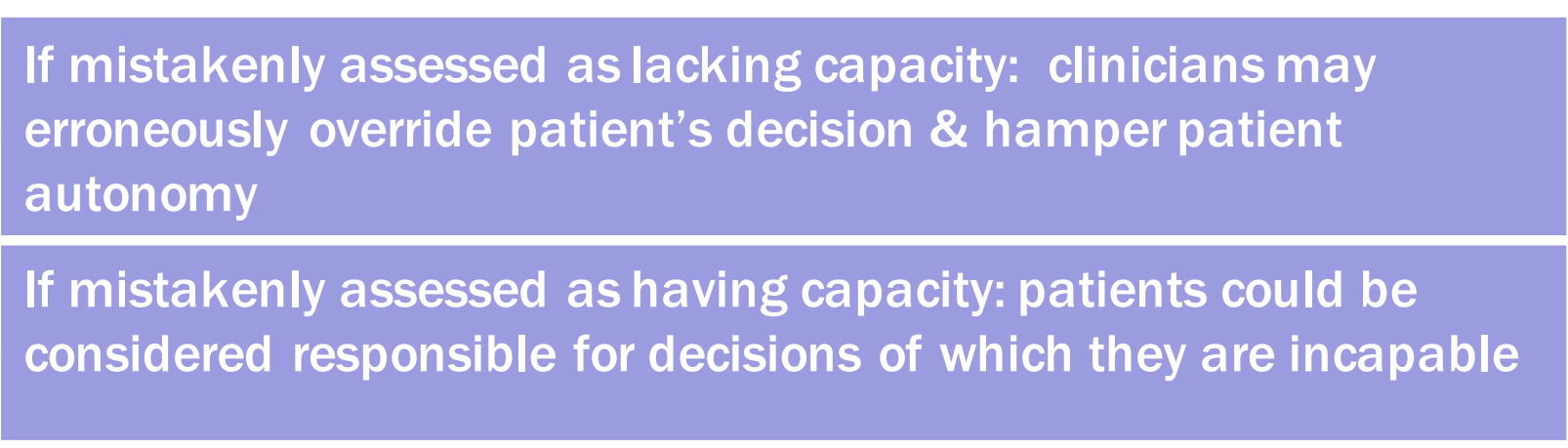

\section{Other Problem Areas in Mental Healthcare AD:}

Nature of illness Psychiatric illness are episodic hence improvement is expected, making it difficult to strictly adhere to $A D$

Implications Recovery: Instructions of refusal to certain treatment could delay recovery

Cost: Due to episodic nature, AD could be expensive

Adherence to AD Due to retained ability to communicate in psychiatric patients, ADs are more likely to be over-ridden

Activation of AD Due to stigma against mental illness, false declaration of incompetence more likely

AD in Mental Healthcare: Real World Evidence:

- $53 \%$ patients reported interest in PAD (Srebnik et al., 2003).

- Only $3 \%$ to $14 \%$ outpatients completed PAD

- $36-53 \%$ clinicians had positive opinions regarding PADs (Swanson, et al 2006)

Practitioner's Concerns with Advance Directive:

Difficulties in accessing documents

Lack of training

Pressure of relatives or partners on treatment decisions

Indian Scenario:

Approach Hybrid - Instructions regarding prescriptive preference, proscriptive preference for future care $\&$ choice of health care proxy

Legal status Binding under MHCA, 2017

\begin{tabular}{l|l} 
Issues with AD in India: & $\begin{array}{l}\text { Unorganized nature of service delivery makes it } \\
\text { challenging to implement and monitor use of AD }\end{array}$
\end{tabular}

Emergency situations $A D$ is applicable in all situations, excluding emergency Issues with availability of $A D$ or its location is unaccounted

Family conflict Conflicts that could arise with family, who are primary care-givers in India is not addressed

Abuse potential Due to lax or non-existent monitoring

Cost $\quad$ Cost of training doctors to implement AD

Cost to strictly monitor use of $A D$

\begin{tabular}{|c|c|c|c|c|c|}
\hline & Germany & Switzerland & Austria & England and Wales & US \\
\hline Approach & Instructional & Instructional & $\begin{array}{l}\text { Not specific to psychiatric } \\
\text { illnesses }\end{array}$ & Instructional & Varies state to state \\
\hline Legal status & $\begin{array}{l}\text { Binding under Mental } \\
\text { Health Act }\end{array}$ & $\begin{array}{l}\text { Binding under Mental Health } \\
\text { Act }\end{array}$ & $\begin{array}{l}\text { Binding under Healthcare } \\
\text { Consent Act }\end{array}$ & $\begin{array}{l}\text { Legally binding under Mental } \\
\text { Capacity Act } 2005\end{array}$ & $\begin{array}{l}\text { Binding - } 1 / 3^{\text {rd }} \text { state have no } \\
\text { legislation for PAD }\end{array}$ \\
\hline Over-ride & $\begin{array}{l}\text { In emergency } \\
\text { admission }\end{array}$ & $\begin{array}{l}\text { - Wishes at admission can } \\
\text { over-ride past agreement. } \\
\text { - Patient's wishes } \\
\text { overridden by court- } \\
\text { ordered treatment }\end{array}$ & $\begin{array}{l}\text { - If patient withdraws it } \\
\text { - If five years pass } \\
\text { without renewal } \\
\text { - In emergencies before } \\
\text { it is located }\end{array}$ & $\begin{array}{l}\text { - If directive in conflictwith } \\
\text { community practice/ } \\
\text { emergency care } \\
\text { - If involuntary commitment } \\
\text { criteria is fulfilled }\end{array}$ & $\begin{array}{l}\text { - If directive in conflictwith } \\
\text { community practice/ } \\
\text { emergency care } \\
\text { - If involuntary commitment } \\
\text { criteria is fulfilled }\end{array}$ \\
\hline
\end{tabular}

Conclusion: In low resource countries with lax monitoring, patients could be coerced to give consent to provisions in AD without fully understanding its repercussions. To avoid this, strict rules and stringent monitoring is essential. Further, significant resources are needed to address the potential conflicts which could arise when AD is followed. Finally, although AD is meant to promote patient autonomy and participation, it is presently derived from "first world principles of individual autonomy" and ignores the collectivistic nature of Indian families and their involvement in patient care.

Campbell LA, Kisely SR. Advance treatment directives for people with severe mental illness. Cochrane Database Syst Rev. 2009 Jan 21:(1):CD005963.

Maître E, Debien C, Nicaise P, Wyngaerden F, Le Galudec M, Genest P, et al. [Advanced directives in psychiatry: A review of the qualitative literature, a state-of-the-art and viewpoints]. Encephale. 2013 Sep:39(4):244-51.

Math SB, Gowda GS, Basavaraju V, Manjunatha N, Kumar CN, Enara A, Gowda M, ThirthalliJ. Cost estimation for implementation of the Mental Healthcare Act 2017. Indian J Psychiatry. 2019 Apr; 61 (Suppl 4):S650-S659.

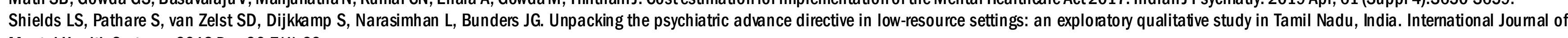
Mental Health Systems. 2013 Dec 26;7(1):29.

Srebnik DS, Russo J, Sage J, Peto T, Zick E. Interest in psychiatric advance directive among users of crisis services and hospitalization. Psychiatr Sew. 2003 Jul;54(7):981-6.

Swanson J, Swart M, Ferron J, Elbogen E, Van Dorn R. Psychiatric advance directives among public mental health consumers in five U.S. cities:prevalence, demand, and correlates, J Am Acad Psychiatry Law. 2006;34(1):43-57. 